\title{
PERENCANAAN PEMBEBANAN KERJA UNTUK MEMENUHI KEBUTUHAN KONSUMEN DENGAN METODE VAM
}

\author{
Ilyas Mas'udin
}

\begin{abstract}
In trade competition for this time, then each factories must be try to completing consumer demand on precise time and quantity. One thing which influence is fluent of production.

In order that production able to work smoothly, so it is necessary to conducting work resposibility to perform work operations in production process. There is exact work responsibility could be optimalizing collar worker productivity. Then, this thing have side effect to production cost. One way to create this situation is with using VAM (Vogel' Approximation menthod). On VAM, this case will be finished equivalen with transportation problem that production capacity and demand said on same squad, same total capacity and same demand. If some time this situation is not completed, then the system must be balanced out first with make capacity or demand Dummy.

So can be alocating every costs until have minimum production and demand costs.

Based on analyst result, then known that with VAM, so labor cost before and after planning, there are a judgment $13.59 \%$ or Rp. 14.976 .345 ,-
\end{abstract}

\section{Key Words : Production, VAM, Demand}

\section{PENDAHULUAN}

Setiap perusahaan yang bergerak dalam bidang manufaktur maupun jasa akan berusaha memperoleh keuntungan yang sebesar-besarnya dengan biaya total seminimal mungkin. Untuk mencapai tujuan tersebut, maka perusahaan harus menjaga kelancaran proses produksinya yaitu dengan melakukan perencanaan produksi sehingga dapat memenuhi permintaan konsumen dalam jumlah dan waktu yang tepat.

Walaupun saat sekarang ini tampak terjadi pengembangaan teknologi produksi yang meningkat cepat, akan tetapi elemen manusia masih saja merupakan komponen kerja yang signifikan dalam sistim produksi. Kemajuan teknologi secara kongkrit membawah perubahan terhadap rancangan kerja dari yang bersifat manual menjadi mekanis ataupun otomatis / terkomputerisasi. Hal ini dilakukan dengan jalan menggantikan fungsi dan peran manusia dengan mesin baik sebagai sumber energi maupun kendali kerja. Sekalipun demikian, baik dalam sektor manufaktur maupun jasa pelayanan, peran manusia masih juga lebih diandalkan sebagai komponen kerja dalam proses produksi.

Perencanaan pembebanan tenaga kerja, maka salah satu tugas pokoknya yang harus dilakukan adalah menetapkan secara rinci dan spesifikasi langkah-langkah operasional trasformasi imput menjadi finished goods yang di kehendaki dan bertujuan untuk menentukan metode terbaik dalam melaksanakan operasi-operasi kerja yang diperlukan dalam proses produksi. 
Langkah perancangan pembebanan tenaga kerja dalam hakekatnya merupakan tahapan paling kritis pada saat perancangan sistim produksi yang baru. Lebih lanjut, pengembangan teknologi baik yang perangkat keras dan lunak yang dapat mengurangi biaya produksi, introduksi produk-produk baru, dan kebutuan untuk bisa untuk mengantisipasi linkungan industri yang dinamis serta suasana kompetisi yang ketat membuat perancangan kembali tata cara dan prosedur kerja menjadi suatu upaya yang vital, penting dan bernilai strategis dalam meraih performans sistem produksi yang lebih baik lagi.

Dalam hal ini, perusahan khususnya dipabrik pengalengan sayur probolinggo menghadapi masalah yaitu: tentang tenaga kerja yang kurang optimal akan menyebabkan terjadinya lonjakan biaya yang besar. Sehingga tidak tercapainya target yang diharapkan, dengan pengadaan pembebanan tenaga kerja mengunakan VAM (Vogel' Approximation menthod) diharapkan nantinya perusahan dapat mengatasi ketidak maksimalnya tersebut.

\section{TINJAUAN PUSTAKA}

\section{Metode Peramalan yang digunakan}

\section{Metode Peramalan Regresi Liner}

Metode Regresi Liner ini memiliki bentuk trend garis lurus dan mempunyai persamaan sebagai berikut :

$\mathrm{Y}=\mathrm{a}+\mathrm{b} \cdot \mathrm{x}$
Dimana :

$\mathrm{Y}=$ Permintaan

$\mathrm{X}=$ Periode waktu

$\mathrm{a} \& \mathrm{~b}=$ Koefisien regresi

untuk menghitung niali $\mathrm{a}$ dan $\mathrm{b}$ digunakan rumus :

$$
\mathrm{a}=\frac{\sum \mathrm{Y}}{\mathrm{n}} \quad \mathrm{b}=\frac{\sum \mathrm{XY}}{\sum \mathrm{X}^{2}}
$$

(Sumber: T.Tani Handoko, 1984, hal 273 )

\section{Metode Exsponential Smoothing}

Peramalan dengan metode Exsponential Smoothing ini menurut (Elsayed, hal 33) lebih cocok digunakan pada data yang cenderung konstan (tidak memiliki trend khusus), dengan diberikan faktor peralatan (Smoothing) yang disimbolkan dengan $\alpha$ yang memiliki nilai antara $0-1$, rumus yang digunakan dalam metode Exsponential Smoothing ini adalah :

a. Single Exsponential Smoothing

$$
\hat{X}_{1}=\alpha X_{t}+(1-\alpha) \hat{X}_{1-1}
$$

Dimana :

$\alpha=$ Faktor Smoothin

$\mathrm{Xt}=$ Permintaan aktual periode $\mathrm{t}$

$\mathrm{X}_{\mathrm{t}}=$ Peramalan

(Sumber : Elsayad, hal 35)

b. Double Exponential Smoothing

$$
\begin{aligned}
& \mathrm{X}_{\mathrm{t}}=\mathrm{X}_{\mathrm{t}}+\alpha \beta \mathrm{X}_{\mathrm{t}-1}+\alpha \beta^{2} \mathrm{X}_{\mathrm{t}-2} \\
& +\ldots .++\alpha \beta \mathrm{X}^{\mathrm{t}-1}{ }_{\mathrm{t}}+\beta^{\mathrm{t}} \mathrm{X}_{0}
\end{aligned}
$$

Dimana :

$$
\begin{aligned}
& X_{t}=\text { Peramalan } \\
& \alpha=\text { Faktor Smoothing }
\end{aligned}
$$


$\beta=1-\alpha$

(Sumber : Elsayed, hal 36)

\section{Exsponential Smoothing dengan Trend}

Bentuk kurva trend eksponensial pada umumnya tidak berbentuk garis lurus tetapi berbentuk garis lengkung. $\mathrm{Hal}$ ini disebabkan adanya penambahan atau pengurangan harga trend tiap-tiap periode tidak selalu sama.

Adapun rumusnya adalah :

$\mathrm{a}_{\mathrm{t}}=2 \mathrm{~F}^{1}{ }_{\mathrm{t}}-\mathrm{F}_{\mathrm{t}}^{2}$

dimana :

$F_{1}=$ estimasi baru ("forecast") untuk periode depan $(t+1)$ yang dibuat pada periode $t$

$a_{\mathrm{t}}=$ nilai aktual dari demand / penjualan untuk periode $t$

$\mathrm{F}_{\mathrm{t}-1}=$ forecast demand $/$ penjualan pada periode sebelumnya, yang mana untuk periode awal $(\mathrm{t}=1)$ maka $\mathrm{F}_{\mathrm{t}-1}$ tidak tersedia. Untuk itu dapat diasumsikan bahwa $F_{t}=A_{t}$

$\alpha=$ konstanta smoothing (pemulusan) yang besarnya $0 \leq{ }^{\alpha} \leq 1$, dimana untuk data yang stabil dapat menggunakan $\alpha$ yang lebih besar dan sebaliknya

( Sumber : skripsi Perancangan Sistem Pendukung Keputusan Untuk Aplikasi Pemilihan Strategi Pemasaran Studi kasus di PT. Ikan Dorang, hal 41 )

\section{Metode Moving Average}

Metode Moving Average ini lebih mudah digunakan dari pada metode regresi linier karena tidak memiliki variabel independent, metode ini meratakan jalur perubahan dengan menggunakan periodeperiode sebelumnya.

Rumus yang digunakan pada metode ini adalah :

$$
X_{t}=\frac{1}{m} \sum_{t=n-m+1}^{n} X
$$

Dimana :

$\mathrm{X}_{\mathrm{t}}=$ Ramalan

$\mathrm{m}$ = Jumlah data yang diratakan

$\mathrm{n}=$ Jumlah total data

$\mathrm{X}$ = Data aktual

(Sumber : Elsayed, hal 27)

Penggunaan jumlah data yang diratakan menurut Narasimhan (1995, hal 28) sekecil mungkin karena semakin besar m maka semakin berkurang kevalidan peramalan

\section{Model Moving Average With Linear Trend}

$\mathrm{F}_{\mathrm{t}}^{1}=\frac{A_{t} \div A_{t-2} \div \ldots \div A_{t-N \neq 1}}{N}$

$\mathrm{F}_{\mathrm{t}}^{2}=\frac{F_{t}^{1} \div F_{t-1}^{1} \div \ldots \div F_{t-N \div 1}^{1}}{N}$

$a_{t}=2 F_{t}^{1}-F_{t}^{1}$

$b_{t}=2 /(N-1) \cdot\left(F_{t}^{1}-F_{t}^{2}\right)$

$F_{t+m}=a_{t}+b_{t} m$

\section{Metode Simple Average}

$$
\mathrm{X}_{\mathrm{t}}=\frac{\Sigma \mathrm{X}}{\mathrm{n}}
$$

Dimana :

$X_{t}=$ Peramalan

$\mathrm{X}=$ Data aktual

$\mathrm{N}=$ Jumlah data

(Sumber : Biegel, 1992, hal 35) 


\section{MEMILIH METODE PERAMALAN YANG PALING TEPAT}

Ada beberapa indikator untuk menentukan kesalahan standart dari peramalan, antara lain :

\section{Mean Square Error}

$$
M S E=\frac{\sum_{i=1}^{n}\left(Y_{i}, Y_{i}^{\prime}\right)^{2}}{n}
$$

dimana :

$\mathrm{Y}_{\mathrm{I}} \quad$ : data aktual periode-I

$\mathrm{Y}_{\mathrm{I}}{ }_{\mathrm{I}} \quad$ : ramalan periode ke-I

n : jumlah data

\section{Standart Error Estimasi ( SEE )}

$\mathrm{SEE}=\sqrt{\frac{\sum_{i=1}^{n}\left(Y_{i}-Y_{{ }_{i}}\right)^{2}}{n-2}}$

dimana :

$\mathrm{Y}_{\mathrm{I}} \quad$ : data aktual pada periode ke-I

$\mathrm{Y}_{\mathrm{I}}{ }_{\mathrm{I}} \quad$ : ramalan periode ke-I

n : jumlah data

\section{Prosentase Kesalahan (PEt)}

$$
P E t=\frac{\left(Y_{i}-Y_{i}^{\prime}\right)^{2}}{Y_{i}}
$$

dimana :

$\mathrm{Y}_{\mathrm{I}} \quad$ : data aktual pada periode ke-i

$\mathrm{n} \quad$ : ramalan periode ke-I

\section{Mean Absolute Percentage Error} ( MAPE )

$$
\text { MAPE }=\frac{\sum\left[\left|e_{t}\right| / D_{t}\right] * 100}{n}
$$

Metode yang terpilih adalah metode MAPE karena mempunyai nilai prosentase error yang terkecil

\section{Prencanaan Agregat}

Langkah-langkah didalam perencanaan agregat adalah :

\section{Menentukan Safety Stock}

Untuk menetukan Safety Stock digunakan rumus :

$\mathrm{SS}=\mathrm{k} \cdot \alpha$

Untuk menentukan Safety Stock digunakan rumus :

$\mathrm{SS}=$ Safety Stock

$\mathrm{K}$ = faktor pengaman (Merupakan tingkat kepercayaan )

$\alpha=$ Standart deviasi permintaan produk

$$
\alpha=\sqrt{\frac{\Sigma(Y-\bar{Y})^{2}}{n-1}}
$$

(Sumber : Narasiman, 1995, hal 216)

2. Mengkonversikan semua data yang dibutuhkan kedalam satuan yang sama, yaitu proses mengkonversikan data menjadi satuan yang sama bisa dalam jam mesin, jam orang, meter, dll

$$
\text { Ada berbagai macam Metode }
$$

Perencanaan Agregat. Klasifikasi metode tersebut dapat didasarkan pada hubungan biayanya dan pada optimal atau tidak optimal hasilnya. Dalam hal ini penulis akan menguraikan secara konseptual salah satu perencanaan agregat yang akan diterapkan (sebagai pemecahan masalah) yaitu VAM

\section{Sedangkan perencanaan agregat} ( rencana beban kerja ) menurut Elsayet dapat dibuat dengan metode sebagai berikut:

* Trasportasi

* Dinamic programming

* Linear programming

dil 
Metode trasportasi menurut Bataraa/Tehan/ dapat diselesaikan dengan algoritma:

VAM (vogel' approximation menthod)

* NCR

* Least Cost

* Moodie

* dll

Masalah perencanaan agregat harus diformulasikan sebagai berikut:

1. kapasitas produksi dan permintaan dinyatakan dalam satuan yang sama.

2. Total kapasitas sama dengan total permintaan dalam horison yang sama. Jika keadaan ini tidak terpenuhi maka harus dibuat kapasitas atau permintaan buatan atau Dummy dengan biaya nol per unit, sehingga sistem jadi seimbang.

3. Semua hubungan biaya linear

Sasarannya adalah meminimumkan biaya produksi dan biaya permintaan.

Langkah-langkah penyelesaian masalah perencanaan agregat dengan VAM menurut Dennis W.M. dan S.C. Narasimhan adalah sebagai berikut:

1. Didefinisikan jenis alternatif yang akan disertakan dalam kegiatan produksi beserta kapasitasnya. Alternatif produksi itu dapat berupa:

* Regular Time (RTt) dengan kapasitas per periode Lt

* Over Time (OTt) dengan kapasitas Mt

* Inventory (It) dengan kapasitas tidak terbatas

Pada metode VAM ini tidak diperhitungkan alternatif subcontracting
2. Tentukan biaya per unit

* Biaya Regular Time (r)

* Biaya Over Time (v)

* Biaya Simpan $(\mathrm{Ch})$

3. Jumlahkan semua kapasitas yang tersedia selama satu horison termasuk inventori awal (jika ada) yaitu jika suatu horison terdapat $\mathrm{n}$ periode.

$$
\text { TotalKapasitas }=\sum_{t=1}^{n}(L t+M t+I t)
$$

Jumlahkan total produksi selama periode yaitu:

$$
\text { TotalPer mintaan }=\sum_{t=1}^{n} Y t
$$

Dimana $\mathrm{Yt}=$ Permintaan pada periode $\mathrm{t}$ Jika total kapasitas lebih besar dari total permintaan maka harus dibuat permintaan fiktif dengan biaya nol (dummy). Bila total permintaan melebihi tital kapasitas maka harus dibuat kapasitas dummy dengan biaya nol. Kenyataannya kapasitas atau permintaan dummy tidak akan pernah diproduksi.

4. Persiapkan sebuah matrik transportasi seperti dibawah ini untuk memfomulasikan masalah.

Matrik pada tabel diatas untuk formulasi masalah dengan horison sebesar 4 periode. Kolom pertama dan terakhir menunjukkan alternatif produksi yang tersedia tiap periode dan kapasitasnya. Kolom kedua, ketiga, keempat, kelima, menunjukkan permintaan yang harus dipenuhi. Total permintaan per periode diletakkan pada baris terakhir yaitu : Y1, Y2, Y3 dan Y4. 
Tiap sel matrik berisi nilai-nilai $r, v$ dan seterusnya yang menunjukkan biaya persatuan produksi jika suatu permintaan dialokasikan ke sel tersebut.

5. Mengalokasikan permintaan tiap periode pada sel biaya terendah lebih dahulu. Pemilihan sel hanya pada sel- sel kolom produksi yang bersangkutan. Bila semua permintaan sudah dialokasikan maka langkah terakhir adalah menjumlahkan total produksi tiap periode (baris $2,3,4,5$ ) dan hasilnya menjadi rencana agregan untuk horison tersebut.

Tabel 1

Matrik Formulasi Masalah Agregat

\begin{tabular}{|c|c|c|c|c|c|c|c|}
\hline \multicolumn{2}{|c|}{ SUMBER } & \multicolumn{4}{|c|}{ Periode Permintaan } & DUMMY & $\begin{array}{l}\text { Kapasitas } \\
\text { Produksi }\end{array}$ \\
\hline \multicolumn{2}{|l|}{$\mathrm{I}_{0}$} & 0 & $\mathrm{Ch}$ & $2 \mathrm{Ch}$ & $3 \mathrm{Ch}$ & 0 & $\mathrm{I}_{0}$ \\
\hline \multirow{4}{*}{$\begin{array}{l}\mathrm{PE} \\
\mathrm{RI} \\
\mathrm{O} \\
\mathrm{DE}\end{array}$} & $\mathrm{RT}_{1}$ & $\mathrm{r}$ & $\mathrm{r}+\mathrm{Ch}$ & $\mathrm{r}+2 \mathrm{Ch}$ & $\mathrm{r}+3 \mathrm{Ch}$ & 0 & $\mathrm{~L}_{1}$ \\
\hline & & & & & & & \\
\hline & $\mathrm{OT}_{1}$ & $\mathrm{v}$ & $\mathrm{v}+\mathrm{Ch}$ & $\mathrm{v}+2 \mathrm{Ch}$ & $\mathrm{v}+3 \mathrm{Ch}$ & 0 & $\mathrm{M}_{1}$ \\
\hline & & & & & & & \\
\hline \multirow{4}{*}{$\begin{array}{l}\mathrm{PE} \\
\mathrm{RI} \\
\mathrm{O} \\
\mathrm{DE}\end{array}$} & $\mathrm{RT}_{1}$ & $\mathrm{r}+\mathrm{Cs}$ & $\mathrm{r}$ & $\mathrm{r}+\mathrm{Ch}$ & $\mathrm{r}+2 \mathrm{Ch}$ & 0 & $\mathrm{~L}_{2}$ \\
\hline & & & & & & & \\
\hline & $\mathrm{OT}_{1}$ & $\mathrm{v}+\mathrm{Cs}$ & $\mathrm{V}$ & $\mathrm{v}+\mathrm{Ch}$ & $\mathrm{v}+2 \mathrm{Ch}$ & 0 & $\mathrm{M}_{2}$ \\
\hline & & & & & & & \\
\hline \multirow{3}{*}{$\begin{array}{l}\text { PE } \\
\text { RI } \\
O\end{array}$} & $\mathrm{RT}_{1}$ & $\mathrm{r}+2 \mathrm{CS}$ & $\mathrm{r}+\mathrm{Cs}$ & $\mathrm{r}$ & $\mathrm{r}+\mathrm{Ch}$ & 0 & $\mathrm{~L}_{3}$ \\
\hline & & & & & & & \\
\hline & $\mathrm{OT}_{1}$ & $\mathrm{v}+2 \mathrm{Cs}$ & $\mathrm{v}+\mathrm{Cs}$ & $\mathrm{v}$ & $\mathrm{v}+\mathrm{Ch}$ & 0 & $\mathrm{M}_{3}$ \\
\hline \multicolumn{8}{|l|}{ DE } \\
\hline \multirow{4}{*}{$\begin{array}{l}\text { PE } \\
\text { RI } \\
O \\
\text { DE }\end{array}$} & $\mathrm{RT}_{1}$ & $\mathrm{r}+3 \mathrm{Cs}$ & $\mathrm{r}+2 \mathrm{Cs}$ & $\mathrm{r}+\mathrm{Cs}$ & $r$ & 0 & $\mathrm{~L}_{4}$ \\
\hline & & & & & & & \\
\hline & $\mathrm{OT}_{1}$ & $\mathrm{v}+3 \mathrm{Cs}$ & $\mathrm{v}+2 \mathrm{Cs}$ & $\mathrm{v}+\mathrm{Cs}$ & $\mathrm{v}$ & 0 & $M_{4}$ \\
\hline & & & & & & & \\
\hline \multicolumn{2}{|l|}{$\mathrm{Yt}$} & Y1 & Y2 & Y3 & Y4 & & \\
\hline
\end{tabular}

$$
\begin{aligned}
\mathrm{r} & =\text { Biaya riguler time } \\
\mathrm{ch} & =\text { Biaya simpan } \\
\mathrm{v} & =\text { Biaya over time } \\
\mathrm{u} & =\text { Biaya sub contrating }
\end{aligned}
$$

Mengalokasikan permintaan tiap periode pada sel biaya terendah lebih dahulu. Pemilihan sel hanya pada sel-sel kolom produksi yang bersangkutan. Bila semua permintaan sudah dialokasikan maka langkah terakhir adalah menjumlahkan total produksi tiap periode (baris $2,3,4,5$ ) dan hasilnya menjadi rencana agregat untuk horison tersebut.

\section{METODOLOGI PENELITIAN}

\section{Data yang Diperlukan}

Adapun data yang diperlukan untuk analisa selanjutnya antara lain : Data Historis, , proses produksi, biaya produksi, data mesin, persediaan, waktu proses, tenaga kerja lembur , data persediaan, tenaga kerja reguler, barang jadi, dan kalender kerja.

\section{Tahapan Pengolahan Data}

1. Melakukan forecasting ( ramalan) terhadap permintaan pada periode yang akan datang dengan MAPE $<10 \%$ 
2. Merencanakan pembebanan kerja dengan menerapkan VAM ( JIP )

\section{HASIL DAN PEMBAHASAN}

3. Mengevaluasi hasil penerapan VAM ( JP ) $\mathrm{BV}<\mathrm{BP}$

Tabel 2

Model Peramalan Terpilih dengan MAPE Terkecil

\begin{tabular}{|c|c|c|c|}
\hline No & $\begin{array}{c}\text { Kode } \\
\text { Kaleng }\end{array}$ & $\begin{array}{c}\text { Metode peramalan } \\
\text { terpilih }\end{array}$ & MAPE \\
\hline 1 & BCL & Doubbel Exponential & $7.90 \%$ \\
\hline 2 & BCC & $\begin{array}{c}\text { Moving Average With } \\
\text { Linear Trend }\end{array}$ & $2.25 \%$ \\
\hline 3 & BCT & $\begin{array}{c}\text { Weighted Moving } \\
\text { Average }\end{array}$ & $4.18 \%$ \\
\hline
\end{tabular}

Adapun hasil peramalan untuk 6 periode perencanaan dengan model peramalan terpilih diatas adalah sebagai berikut :

Tabel 3

Hasil Peramalan untuk 12 periode yang akan datang

\begin{tabular}{|c|c|c|c|c|c|}
\hline \multirow{2}{*}{ Periode } & \multicolumn{5}{|c|}{ Ramalan Permintaan } \\
\cline { 2 - 6 } & PE 30/1 & PE 40/1 & PR 30/1 & PR 45/1 & $\begin{array}{c}\text { PR } \\
\mathbf{6 0 / 1}\end{array}$ \\
\hline April 2001 & 323,202 & 624,635 & 106,603 & 724,076 & 55,106 \\
\hline Mei & 318,999 & 638,466 & 112,152 & 715,062 & 55,186 \\
\hline Juni & 314,796 & 652,604 & 117,701 & 706,048 & 55,266 \\
\hline Juli & 310,593 & 667,055 & 123,250 & 697,034 & 55,347 \\
\hline Agust & 306,390 & 681,826 & 128,799 & 688,020 & 55,427 \\
\hline September & 302,187 & 696,924 & 134,347 & 679,006 & 55,508 \\
\hline Oktober & 297,984 & 712,356 & 139,896 & 669,992 & 55,588 \\
\hline November & 293,781 & 728,130 & 145,445 & 660,978 & 55,669 \\
\hline Desember & 289,578 & 744,253 & 150,944 & 651,964 & 55,749 \\
\hline Jan. 2002 & 285,375 & 760,734 & 156,543 & 642,950 & 55,829 \\
\hline Pebruari & 281,172 & 777,579 & 162,092 & 633,936 & 55,910 \\
\hline Maret & 276,969 & 794,797 & 167,641 & 624,922 & 55,991 \\
\hline Jumlah & $\mathbf{3 0 6 1 , 0 2 6}$ & $\mathbf{8 4 7 9 , 3 5 9}$ & $\mathbf{1 6 4 5 , 4 6 3}$ & $\mathbf{8 0 9 3 , 9 8 8}$ & $\mathbf{6 6 6 , 5 8 1}$ \\
\hline
\end{tabular}

Tabel 4

Hasil Ramalan yang telah disesuaikan dengan Prosentase Cacat

\begin{tabular}{|c|l|c|c|c|c|c|}
\hline \multirow{2}{*}{ Periode } & \multirow{2}{*}{ Bulan } & \multicolumn{5}{|c|}{ Jenis Produk } \\
\cline { 3 - 7 } & & PE 30/1 & PE 40/1 & PR 30/1 & PR 45/1 & PR 60/1 \\
\hline 1 & April'01 & 324.83 & 627.77 & 107.14 & 727.71 & 55.38 \\
\hline 2 & Mei & 320.60 & 641.67 & 112.72 & 718.65 & 55.46 \\
\hline 3 & Juni & 316.41 & 655.88 & 118.29 & 709.59 & 55.54 \\
\hline 4 & Juli & 312.15 & 670.41 & 123.86 & 700.54 & 55.63 \\
\hline 5 & Agust & 307.92 & 685.25 & 129.45 & 691.47 & 55.71 \\
\hline 6 & Sept & 303.71 & 700.43 & 135.02 & 682.42 & 55.78 \\
\hline 7 & Okt & 299.48 & 715.94 & 140.59 & 673.66 & 55.87 \\
\hline 8 & Nov & 295.26 & 731.79 & 146.17 & 664.31 & 55.95 \\
\hline 9 & Des & 291.03 & 747.99 & 151.75 & 655.24 & 56.02 \\
\hline 10 & Jan'02 & 286.80 & 764.55 & 157.33 & 646.18 & 56.11 \\
\hline 11 & Feb & 282.58 & 781.48 & 162.90 & 637.12 & 56.19 \\
\hline 12 & Maret & 278.36 & 788.74 & 168.48 & 628.06 & 56.27 \\
\hline \multicolumn{2}{r}{ Total } & $\mathbf{3 6 1 9 . 1 2 2}$ & $\mathbf{8 5 1 2 . 9 6 9}$ & $\mathbf{1 6 5 3 . 7 3 2}$ & $\mathbf{8 1 3 4 . 6 6 1}$ & $\mathbf{6 9 9 . 9 3 0}$ \\
\hline
\end{tabular}




\section{Rencana Agregat}

Tabel 5

Rencana Agregat Periode April 2001 - Maret 2002

\begin{tabular}{|c|c|c|c|c|c|c|}
\hline \multirow{2}{*}{ Periode } & \multirow{2}{*}{ Permintaan } & \multirow{2}{*}{ inventory } & $\sum$ hari kerja & \multicolumn{2}{|c|}{ Produksi } & \multirow{2}{*}{$\begin{array}{c}\text { Total } \\
\text { produksi }\end{array}$} \\
\hline 0 & & 16641 & & & & \\
\hline 1 & 18197 & 1802 & 26 & 5735 & - & 5735 \\
\hline 2 & 18205 & 1802 & 27 & 15336 & - & 15336 \\
\hline 3 & 18305 & 1802 & 30 & 17040 & - & 17040 \\
\hline 4 & 18364 & 1802 & 28 & 15904 & 2460 & 18364 \\
\hline 5 & 18425 & 1802 & 31 & 17608 & 817 & 18425 \\
\hline 6 & 18489 & 1802 & 30 & 17040 & 1449 & 18489 \\
\hline 7 & 18556 & 1802 & 30 & 17040 & 1516 & 18556 \\
\hline 8 & 18626 & 1802 & 30 & 17040 & 1586 & 18626 \\
\hline 9 & 18699 & 1802 & 30 & 17040 & 2684 & 19724 \\
\hline 10 & 18775 & 1802 & 25 & 14200 & 3550 & 17750 \\
\hline 11 & 18855 & 1802 & 30 & 17040 & 1815 & 18855 \\
\hline 12 & 18938 & 1802 & 28 & 15904 & 3034 & 18938 \\
\hline
\end{tabular}

Dari hasil yang ada dapat dianalisa bahwa untuk tiap-tiap periode membutuhkan produksi sebesar yang talah tertera pada tabel 5.3, dengan jam kerja reguler pada periode 1 sampai dengan periode 3 , untuk periode 4 sampai dengan periode 12 selain reguler time juga memerlukan over time, dengan jumlah tenaga kerja sebesar 71 orang.

\section{Perencanaan Disagregat}

Tabel 7

Jadwal Induk Produksi

\begin{tabular}{|l|c|c|c|c|c|}
\hline \multirow{2}{*}{ Periode } & \multicolumn{5}{|c|}{ Kode Produksi } \\
\cline { 2 - 6 } & PE 30/1 & PE 40/1 & PR 30/1 & PR 45/1 & PR 60/1 \\
\hline April 2001 & 279,048 & 324,906 & 38,888 & - & 15,713 \\
\hline Mei & 367,214 & 756,274 & 135,525 & 403,745 & 67,050 \\
\hline Juni & 308,895 & 640,527 & 115,909 & 792,9 & 54,525 \\
\hline Juli & 303,071 & 656,535 & 121,896 & 654,583 & 53,296 \\
\hline Agustus & 339,290 & 759,285 & 143,958 & 768,081 & 61,766 \\
\hline September & 343,981 & 803,120 & 155,793 & 771,174 & 63,440 \\
\hline Oktober & 328,531 & 798,759 & 158,164 & 740,827 & 61,798 \\
\hline November & 347,344 & 875,619 & 176,510 & 776,529 & 66,072 \\
\hline Desember & 352,610 & 948,843 & 195,320 & 807,573 & 69,836 \\
\hline Januari 2002 & - & - & - & - & 1814,335 \\
\hline Pebruari & 326,421 & 919,931 & 186,056 & 724,026 & - \\
\hline Maret & 323,474 & 891,905 & 196,312 & 728,79 & - \\
\hline
\end{tabular}

Tabel 8

\section{Inventory Akhir}

\begin{tabular}{|l|c|c|c|c|c|}
\hline \multirow{2}{*}{ Periode } & \multicolumn{5}{|c|}{ Kode Produksi } \\
\cline { 2 - 6 } & PE 30/1 & PE 40/1 & PR 30/1 & PR 45/1 & PR 60/1 \\
\hline April 2001 & 98 & 430 & 106 & 1175 & 42 \\
\hline Mei & 52,218 & 127,136 & 37,748 & 447,29 & 2,333 \\
\hline Juni & 98,832 & 245,74 & 60,553 & 132,385 & 13,923 \\
\hline Juli & 91,31 & 230,387 & 58,172 & 217,695 & 12,908 \\
\hline Agustus & 82,177 & 216,512 & 56,208 & 171,738 & 10,507 \\
\hline
\end{tabular}




\begin{tabular}{|l|c|c|c|c|c|}
\hline September & 113,695 & 290,467 & 70,716 & 248,349 & 16,563 \\
\hline Oktober & 153,424 & 393,237 & 91,923 & 337,103 & 24,223 \\
\hline November & 182,475 & 476,056 & 109,063 & 404,270 & 30,161 \\
\hline Desember & 234,559 & 619,855 & 139,403 & 516,489 & 40,283 \\
\hline Januari 2002 & 296,139 & 820,738 & 182,973 & 668,822 & 54,099 \\
\hline Pebruari & 9,339 & 56,188 & 25,643 & 23,642 & 1812,324 \\
\hline Maret & 53,180 & 187,671 & 48,799 & 110,548 & 1821,457 \\
\hline
\end{tabular}

Tabel 9

Total Penghematan Biaya

\begin{tabular}{|c|c|c|c|}
\hline \multirow{2}{*}{ Kode Produksi } & \multicolumn{2}{|c|}{ Biaya (Rupiah) } & \multirow{2}{*}{ Penghematan } \\
\cline { 2 - 3 } & $\begin{array}{c}\text { Kondisi } \\
\text { Lama }\end{array}$ & Kondisi Baru & \\
\hline PE 30/1 & $80.542,09$ & $48.472,00$ & $32.070,09$ \\
\hline PE 40/1 & $673.106,39$ & $120.652,60$ & $552.453,79$ \\
\hline PR 30/1 & $195.670,88$ & $74.658,00$ & $121.012,88$ \\
\hline PR 45/1 & $608.470,55$ & $370.245,60$ & $238.224,95$ \\
\hline PR 60/1 & $69.696,28$ & $5.832,80$ & $63.863,48$ \\
\hline Jumlah & $\mathbf{1 . 6 2 7 . 4 8 6 , 1 9}$ & $\mathbf{6 1 9 . 8 6 1 , 0 0}$ & $\mathbf{1 . 0 0 7 . 6 2 5 , 1 9}$ \\
\hline
\end{tabular}

Jadi total penghematan biaya setelah menerapkan JIP adalah Rp. 1.007.625,19 atau setara dengan: $\frac{1.007 .625,19}{1.627 .486,19} X 100 \%=61,91 \%$

\section{KESIMPULAN}

1. Jumlah tenaga kerja yang diperoleh dari pembahasan sebanyak 68 tenaga kerja, dengan kebutuhan konsumen sebanyak 81583 jam selama 6 periode

2. Setelah dilaksanakan analisa, bahwa biaya tenaga kerja sebelum dan sesudah perencanaan ada penghematan sebesar $13.59 \%$ atau sebesar Rp. 14.976.345,yaitu:

$>$ Untuk saat ini sebelum perencanaan dengan menggunakan metode transportasi sebanyak 62 tenaga kerja, dengan biaya sebesar Rp.110193793,-
Sesudah (Dengan menggunakan Metode transportasi) didapatkan jumlah tenaga kerja sebanyak 68 orang dengan biaya sebesar Rp 95217448,-

$=$ Rp. $110193793-$ Rp. 95217448

$=$ Rp. 14.976.345,-

Jadi penghematan

$$
\begin{gathered}
=\frac{110193793-95217448}{110193793} \times 100 \% \\
=\operatorname{Rp~} 14.976 .345,- \\
=13.59 \%
\end{gathered}
$$

\section{DAFTAR PUSTAKA}

Assauri Sofjan, 1993, "Manajemen Produksi dan Operasi" edisi ke empat Fakultas Ekonomi, Universitas Indonesia.

Elyased A. E., Thomas O. Boucher.

"Analysis and Control of 
Productiont System” Edisi ke tujuh, Prentice Hall International Edition.

Frederick S. H., Gerald J. Lieberman. "Introductions Research" edisi ke lima, Mc graw Hill International Edition.

P. Siagian, 1987, "Penelitian Operasional" Universitas Indonesia.

Pangestu Subagyo, Marwan Asri, T. Hani Handoko, 1991, "Dasar-Dasar Operations Research", edisi ke dua, BPFE Yogyakarta.
Richard J. Tersine, "Principles Of Inventory and Marerials Management" edisi ke tiga, Nort-Holland New York.

Taha, H. A., "Riset Operasi" edisi ke lima, Binarupa Aksara. 